\title{
THE EFFECT OF A GREEK TRADITIONAL DANCE PROGRAM ON THE MOTOR COMPETENCE OF CHILDREN WITH AUTISM SPECTRUM DISORDER
}

\author{
Evaggelia-Anna Marouli², \\ Vasiliki Kaioglou, ${ }^{1}$, \\ Vasilios Karfis ${ }^{1}$, \\ Antonios Kambas', \\ Maria Koutsouba', \\ Fotini Venetsanou ${ }^{1 i}$ \\ ${ }^{1}$ National and Kapodistrian University of Athens, \\ School of Physical Education and Sport Science, \\ Greece \\ ${ }^{2}$ Democritus University of Thrace, \\ Department of Physical Education \& Sports Science, \\ Greece
}

\begin{abstract}
:
It is usual for individuals with autism spectrum disorder (ASD) to demonstrate deficits in motor behavior. Participation in movement programs has been suggested to elicit improvements in their motor competence (MC) level. The aim of the present study was to examine the effect of a Greek traditional dance (GTD) program on the MC of 6-14-yearold children with ASD. The study design included eight participants (two girls, six boys), who were randomly allocated into two equal-sized groups, group A (its members participated only in the regular Physical Education lessons provided by their school) and group B (its members additionally followed an 8-week GTD program of two 40-min sessions per week). Children's MC was assessed prior and immediately after the completion of the GTD program by the Bruininks- Oseretsky Test of Motor Proficiency (BOT-2 SF). Due to study's small sample size and participants' heterogenous ASD characteristics, the results will be interpreted as outcomes of multiple single case studies. Overall, it was observed that the MC of all participants was considerably poor; however, members of group B made greater improvements in both the total BOT-2 point score and most item raw scores compared to those of group A, with balance and body coordination skills presenting the greater improvements. Even though the results of this study stress the positive effect of GTD on the MC of children with ASD, future studies employing
\end{abstract}

${ }^{i}$ Correspondence: email fvenetsanou@phed.uoa.gr 
wider sample sizes and/or implementing longer programs are required to further confirm its merit.

Keywords: intervention program, motor skills, motor proficiency, BOT-2

\section{Introduction}

Apart from common stereotypical behaviors that individuals with autism spectrum disorder (ASD) face, such as unusual attachments to objects, obsessions, compulsions, self-injurious behaviors, hand flapping, finger movements, rocking, twirling (Pan, Tsai, \& Chu, 2009; Newschaffer et al., 2007; Volkmar, Chawarska, \& Klin, 2005), a considerable large proportion of children with ASD exhibit motor deficits and/or impairments compared to their typically developing peers (Gandotra et al., 2020; Gkotzia, Venetsanou, \& Kambas, 2017; Liu, Hamilton, Davis, \& ElGarhy, 2014; Pan, 2014). Particularly, even though children with ASD present differences in respect of the time they develop basic motor skills and the quality of those skills (Green et al., 2009; Pan, 2014; Provost, Lopez, \& Heimerl, 2007), in the recent systematic review of Gandotra et al. (2020), it was shown that for most of these children motor delays are apparent from the early developmental stages and persist throughout the period of childhood. In this review, it was also revealed that children with ASD face restrictions, especially when performing coordinated movement patterns as well as tasks that require refined locomotor and object control skills (Gandotra et al., 2020). Due to several motor challenges, they face and the distinct difficulties in social interaction with their peers (Lai, Lombardo, Chakrabarti, \& BaronCohen, 2013), children with ASD usually avoid participation in physical activity (PA) and sport (Pan, 2008). Unfortunately, significant others in these children' life usually neglect the nurture of their motor development, even though the early onset and the severity of their motor delays affect them, sometimes in a larger extent, than their social/communication problems do (Harris, 2017; MacDonald, Lord, \& Ulrich, 2014).

Interestingly, Physical Education (PE) (Imankhah, Khanzadeh, \& Hasirchaman, 2018; Najafabadi et al., 2018) and other organized PA, such as swimming (FragalaPinkham, Haley, \& O'Neil, 2011), horse riding (Wuang, Wang, Huang, \& Su, 2010), taekwondo (Kim et al., 2016), cycling (Shim, Newman, Haegela, \& Varnado, 2019), pilates (Saracoglu, \& Sirinkan, 2016), therapeutic ice-skating (Casey, QuennevilleHimbeault, Normore, Davis, \& Martell, 2015), table tennis (Pan et al., 2017), have been found to have a positive influence on motor skills (mainly balance ones) and/or parameters of physical fitness of children with ASD.

Attempting to support these children' development, many decades ago, researchers highlighted the beneficial effect of therapeutic dance programs on several aspects of it, e.g., motor and/or psychosocial (Kalish-Weiss, 1982; Parteli, 1995). Generally, programs based on movement and music are thought to be advantageous, since they can be an enjoyable and, most importantly, an effective means of developing 
motor skills and coordination in children with ASD (Imankhah et al., 2018; Sanglakh Goochan Atigh, Akbarfahimi, \& Alizadeh Zarei, 2017).

Greek traditional dance (GTD), an activity employing rhythmic movements accompanied by traditional music, has been suggested to contribute to the development of children' motor skills (Venetsanou, \& Kambas, 2004). Since teaching methods utilized in GTD can be simplified and adjusted according to individual needs, the implementation of relative programs may be suitable and useful for children with ASD, too. However, there is only one published study that has incorporated GTD in a program targeting this specific population (Arzoglou et al., 2013) so far. Arzoglou et al. (2013) found that a program based on GTD improved indices of neuromuscular coordination in children with ASD. To our knowledge there is no study having examined the effect of GTD on both fine and gross motor skills of children with ASD. Filling this gap in research, the present study attempts to investigate the effectiveness of an 8-week GTD program on the motor competence (MC) of children diagnosed with ASD. According to available evidence, it was assumed that children' MC will be at a considerably low level; however, it will be positively affected by the delivery of the GTD program.

\section{Material and Methods}

\subsection{Participants}

Eight 6-14-year-old children diagnosed with ASD (2 girls and six boys) were recruited from one Special education school located in the residential area of East Attica, Greece. Apart from being diagnosed with this disorder, participants were not facing additional health problems. According to study's research design, they were randomly divided into two groups: group A $(n=4)$ and group B $(n=4)$ group. Prior to data collection, participants' parents or legal guardians were thoroughly informed about the purposes and procedures of the research and they were asked to submit their written consent.

\subsection{Measures}

Participants' MC was assessed by the short version of the second edition of BruininksOseretsky Test of Motor Proficiency (BOT-2 SF; Bruininks, \& Bruininks, 2005), a test that detects potential disorders in the performance of children's fine and gross motor skills. The BOT-2 SF is comprised of 14 items taken from the pool of the 53 items included in the long form of the instrument. Participants' performance in each item is recording in raw scores, based on criteria such as time needed to complete the test, number of correct repetitions, number of mistakes, etc. These scores are converted to point scores and eventually all items' point scores are summed up to provide the total BOT-2 point score, which represents participants' MC level. Although the instrument's scoring system also provides a standardized score based on age- and sex-specific norms, in this study only total BOT-2 point score and items' raw scores will be used to interpret the results (BOT-2 subscales, items and scoring are presented in Table 1). The psychometric properties of 
the instrument are sufficiently supported (Bruininks, \& Bruininks, 2005; Lucas et al., 2013). Before its use in Greek population, its validity and reliability were also examined (Venetsanou, Voukias, Zavolas, Mitsios, \& Kambas, 2016).

\subsection{Procedure}

Participants of group B, along with the intervention program, regularly attended the two weekly PE lessons provided by their school curriculum, whereas those of group A continued their usual exercise routine, which only included participation in PE. MC measurements for both groups were conducted in two time points, before (premeasurement; October 2019) and after the completion of the GTD program (postmeasurement; December 2019) in school's facilities during school's regular timetable. Each participant was assessed individually, during one session of approximately 20-30 minutes, by one trained examiner according to the guidelines provided in the BOT-2 SF manual.

\subsection{Greek Traditional Dance (GTD) program}

The intervention program was 8-week long delivered at the frequency of two 40-min sessions per week. It was based on the principle of individualized learning; therefore, it was designed in line with the participants' needs and characteristics (Arzoglou et al., 2013; Wengrower, 2010) and implemented separately to each participant. The selection of dances taught was based on their morphology and typology (Tyrovola, 2001); whereas, the content of the program was informed by the combination of the imitative- and the music/movement method (Mathe, Koutsouba, \& Lykesas, 2008). As long as the first method is concerned, the technique of mirroring was adopted, since it has been found to be suitable for teaching dance to individuals with ASD (Hildebrandt, Koch, \& Fuchs, 2016; Wengrower, 2010). For its application, the student is asked to position him/herself right opposite to the teacher and try to replicate, as accurately as he/she can, every single move the teacher performs, so to imitate the moving reflection of teacher's idol to an imaginary mirror. The music/movement approach, based on techniques such as experimentation, exploration, observation, free movement, creativity, spontaneity, and improvisation (Venetsanou, Donti, \& Koutsouba, 2014), is considered a creative teaching method commonly used in GTD programs (Lykesas, Dania, Koutsouba, Nikolaki, \& Tyrovola, 2017).

\subsection{Data analysis}

Total- and item- BOT-2 point scores were computed for all participants for both measurements. Proportion of improvement (in \%) for total BOT-2 point score and item raw scores from pre- to post- measurement was also calculated. Nevertheless, due to both the heterogeneity that children with ASD present (Lenroot \& Yeung, 2013; Mottron \& Bzdok, 2020) and the small sample of the study, the results of the study will be interpreted 
as outcomes of multiple single case studies. In particular, the results will focus on depicting participants' MC level as well as observing group differences.

\section{Results}

Participants of group B attended all 16 sessions of the intervention program, showing high fidelity to it. Though it was not a measurable parameter of this study, it was observed that participation in the program was a very pleasant experience for children, as they were constantly expressing their willingness and impatience to participate in every session.

Total BOT-2 point score and item raw scores for pre- and post-measurement for groups A and B are summarized in Table 1. According to pre-measurement scores heterogeneity was observed among the study's participants both (a) between groups; lowest-highest score difference of 41 points, (b) within groups; lowest-highest score difference of 39 and 29 points for groups $B$ and A, respectively.

Pre-measurement total BOT-2 scores indicated that all participants presented a considerable low MC level (range of 7-36 points). Overall, they scored very low in the items of "Folding a paper", "Dribbling a ball", "Jumping in place", "One leg stationary hop", "Knee push-ups", and "Sit-ups".

In reference to the comparison between pre- and post-measurements, it was observed that three out of four participants of group A showed some improvement in their total BOT-2 scores (ranging from 3\%-22\%); on the contrary, all four participants of group B were improved, exhibiting a considerably large proportion of positive change in their scores (ranging from 30\%-80\%). All four group B members raised their scores in post- measurement for "Tapping feet and fingers" (range of 28\%-100\%) and "Standing on a balance beam" (range of $42 \%-66 \%$ ), whereas increasing post- measurement scores were only observed for one member of the Group A for the first item (50\%) and two members for the latter one (range of 17\%-21\%). For "Copying a square", "Walking forward on a line" and "One leg stationary hop", the majority (three out of four) group B members scored higher after the application of the intervention (range of $25 \%-200 \%$ ), but none of group A did so. For "Jumping in place" item, half (two out of four) group B members bettered their post-measurements scores (range of 33\%-100\%), but, similarly, none of group A members did. Only for "Transferring pennies", it was recorded that less participants of group B compared to those of group A positively changed their scores from pre- to post- measurement (two vs four); however, the proportion of improvement for group B members was higher (group B: 33\%-71\%, group A: $12.5 \%-66 \%$ ). For the rest items, equal number of participants from each group made some improvement; specifically, one of each group increased their post-measurement scores in "Dribbling a ball” (group A: 25\%, group B: 50\%), "Knee push-ups (group A: 400\%, group B: 200\%) and "Sit-ups" (group A: 25\%, group B: 40\%), and, similarly, two in "Copying a star" (group 
A: 33\%-100\%, group B: 50\%-400\%) and "Dropping and catching a ball" (group A: 33\%$33 \%$, group B: 50\%-100\%).

Regarding group A, when participants' pre-measurement score was "zero", this score remained as it was in post-measurement; therefore, no improvement was recorded for these participants; in contrast, for group B, almost half of the pre-measurement "zero" scores were positively changed after the application of the intervention program. In "Drawing a line on a zig-zag path" and "Folding a paper", none of the study's participants was improved; specifically, in the latter, all of them, regardless the group they belonged to, failed to score in both measurements.

Table 1: Total BOT-2 point score and item raw scores for pre- and post-measurement for groups A and B

\begin{tabular}{|c|c|c|c|c|c|c|c|c|c|c|c|c|c|c|c|c|}
\hline \multirow{3}{*}{$\begin{array}{l}\text { BOT-2 SF } \\
\text { subscales/items }\end{array}$} & \multicolumn{8}{|c|}{ Group A } & \multicolumn{8}{|c|}{ Group B } \\
\hline & \multicolumn{4}{|c|}{$\begin{array}{l}\text { Pre-measurement } \\
\text { raw score }\end{array}$} & \multicolumn{4}{|c|}{$\begin{array}{c}\text { Post-measurement } \\
\text { raw score }\end{array}$} & \multicolumn{4}{|c|}{$\begin{array}{l}\text { Pre-measurement } \\
\text { raw score }\end{array}$} & \multicolumn{4}{|c|}{$\begin{array}{c}\text { Post-measurement } \\
\text { raw score }\end{array}$} \\
\hline & P1 & P2 & P3 & $\mathbf{P 4}$ & P1 & P2 & $\mathrm{P}_{3}$ & $\mathbf{P 4}$ & $\mathbf{P 5}$ & P6 & P7 & P8 & P5 & P6 & P7 & P8 \\
\hline \multicolumn{17}{|l|}{ Fine manual control } \\
\hline $\begin{array}{l}\text { Drawing a line on a } \\
\text { zigzag path }^{\mathrm{a}}(0-21)\end{array}$ & 9 & 21 & 3 & 10 & 6 & 21 & 2 & 8 & 5 & 0 & 21 & 5 & 3 & 0 & 21 & 3 \\
\hline Folding a paper $(0-12)$ & 0 & 0 & 0 & 0 & 0 & 0 & 0 & 0 & 0 & 0 & 0 & 0 & 0 & 0 & 0 & 0 \\
\hline Copying a star ${ }^{\mathrm{b}}(0-5)$ & 1 & 0 & 3 & 3 & 2 & 0 & 3 & 4 & 3 & 4 & 0 & 2 & 3 & 4 & 3 & 3 \\
\hline Copying a square ${ }^{b}(0-5)$ & 0 & 0 & 4 & 3 & 0 & 0 & 4 & 4 & 0 & 5 & 0 & 0 & 1 & 5 & 4 & 1 \\
\hline \multicolumn{17}{|l|}{ Manual coordination } \\
\hline $\begin{array}{l}\text { Transferring pennies } \\
(0-20)\end{array}$ & 5 & 3 & 8 & 10 & 8 & 5 & 9 & 12 & 6 & 9 & 5 & 7 & 8 & 8 & 3 & 12 \\
\hline $\begin{array}{l}\text { Dropping and catching } \\
\text { a ball }{ }^{\mathrm{b}}(0-5)\end{array}$ & 0 & 1 & 3 & 3 & 0 & 1 & 4 & 4 & 0 & 1 & 0 & 2 & 0 & 2 & 1 & 2 \\
\hline Dribbling a ball (0-10) & 0 & 3 & 6 & 4 & 0 & 3 & 5 & 5 & 0 & 1 & 0 & 0 & 0 & 2 & 0 & 0 \\
\hline \multicolumn{17}{|l|}{ Body coordination } \\
\hline Jumping in place $(0-5)$ & 0 & 0 & 5 & 0 & 0 & 0 & 5 & 0 & 1 & 3 & 0 & 0 & 1 & 4 & 0 & 1 \\
\hline $\begin{array}{l}\text { Tapping feet and } \\
\text { fingers }(0-10)\end{array}$ & 2 & 0 & 10 & 4 & 3 & 0 & 10 & 3 & 7 & 6 & 0 & 4 & 9 & 10 & 4 & 8 \\
\hline \multicolumn{17}{|l|}{ Balance } \\
\hline $\begin{array}{l}\text { Walking forward on a } \\
\text { line }(0-6)\end{array}$ & 1 & 3 & 6 & 4 & 1 & 3 & 4 & 2 & 4 & 4 & 2 & 2 & 5 & 5 & 2 & 4 \\
\hline $\begin{array}{l}\text { Standing on a balance } \\
\text { beam }(0-10)\end{array}$ & 1.1 & 2.3 & 4.6 & 2.3 & 0.8 & 1.5 & 5. & 2.8 & 4.5 & 4.2 & 3.7 & 1.5 & 7.2 & 6 & 5.3 & 2.5 \\
\hline \multicolumn{17}{|l|}{ Strength and agility } \\
\hline $\begin{array}{l}\text { One leg stationary hop } \\
(0-50+)\end{array}$ & 0 & 2 & 28 & 4 & 0 & 1 & 16 & 0 & 2 & 5 & 0 & 0 & 6 & 8 & 0 & 1 \\
\hline Knee push-ups $(0-36+)$ & 0 & 0 & 1 & 1 & 0 & $\underline{0}$ & 4 & 0 & 4 & 0 & 0 & 0 & 3 & 2 & 0 & 0 \\
\hline Sit-ups $(0-36+)$ & 0 & 2 & 4 & 3 & 0 & 1 & 5 & 1 & 5 & 10 & 3 & 0 & 7 & 9 & 0 & 0 \\
\hline $\begin{array}{l}\text { Total BOT-2 point score } \\
(0-88 \text { points })\end{array}$ & 9 & 10 & 48 & 29 & 11 & 11 & 47 & 30 & 22 & 36 & 7 & 15 & 31 & 47 & 15 & 24 \\
\hline
\end{tabular}

Note: The eight participants of the study are referred as " $\mathrm{P}$ " with a corresponding number from 1-8. For the 14 items, raw scores are listed (the range of each raw score is presented along with the name of the corresponding item).

aNumber of errors; a lower score denotes higher performance.

'For item's point score the respective raw score is duplicated. 
Decreases in post-measurement scores were more often observed for group A members; for both the total BOT-2 and ten item scores at least one group A member presented a decreased respective score. Group B members obtained lower scores in postcompared to pre-measurement in four items ("Drawing a line on a zig-zag path" [two], "Transferring pennies" [two], "Knee push-ups" [one] and "Sit ups" [one]). For three items, ("Copying a star", "Copying a square", "Jumping in place") none of the eight participants' scores decreased between the measurement points.

\section{Discussion}

The present study examined whether a dance program, informed by GTD, could have a positive effect on the MC of children with ASD. Based on the results of the multiple single subject design adopted in this study, it was observed that the general MC level of all participants was considerably low; however, children who underwent the GTD program showed greater improvement in their MC compared to their peers that did not participate in it. Balance and body coordination skills were mostly affected by the program.

Starting with the assessment of participants' MC, the very poor MC, implying the presence of deficiencies in those children's motor development, should be noted. Specifically, all of them were mostly challenged performing tasks that require strength, agility, and coordination; however, the most difficult task for them was to fold a paper, showing their poor skills in fine manual control, too. In the study of Pan (2014), in which the MC of 10-17-year-old children with ASD was assessed using the BOT-2, similarly low scores were recorded (mean total BOT-2 score: 30 points, maximum score: 50 points). Alike, in the more recent report of Pan at al. (2017), the study's participants (9-11-yearold) received total BOT-2 scores between 40-50 points, further conforming the finding that children with ASD face several motor challenges. The fact that our participants demonstrated even lower MC level than those in the above reference studies could be explained by the presence of younger children in our sample. Furthermore, it is likely the heterogeneity of ASD characteristics between our participants and those in the other two studies was essential. The finding that children with ASD present deficits in the development of their motor skills is also supported by several relevant studies (Gkotzia et al., 2017; Liu et al., 2014; Pan, 2014). Apart from reasons related to physiological constrains derived from their condition, these deficits could be partially attributed to the fact that significant others in these children' life usually overlook that specific part of their development (Gandotra et al., 2020). Given that the refined motor skills facilitate common tasks performed in everyday life and they are related to children' PA participation -at least in typically developing peers- (Jaakola et al., 2019), the above acknowledgement leads to the thought that the education of children with ASD should incorporate systematic efforts (e.g., programs, interventions) to effectively nurture this important part of their development. 
In reference to programs that may be useful in that direction, this study revealed that the implementation of a personalized dance program informed by GTD was effective in inducing improvements in all children' $\mathrm{MC}$, even though the very low initial MC level of children did not allow for major modifications to occur. Nevertheless, the positive change in children's scores after the implementation of the intervention program should be considered important, since it was considerably greater than this observed for children who did not participated in the program. Specifically, for most participants, the influence of the GTD program was more obvious mainly in tasks requiring balance and body coordination. Improvement was less for some tasks that require manual coordination, power, and agility, whereas it was least for most fine manual control tasks. Acknowledging that the GTD program was not focused on all aspects of MC, the finding that our participants were not equally improved in all tasks is understandable. Probably, the impact of the program would be even wider if it was larger in duration and frequency. However, overall, the program has some merit, considering both that considerable improvements recorded, even in cases in which children presented the lowest possible level ("zero" score) and also reductions in children' scores after the implementation of the program were rare. Apart from the above recorded elements, it seems that the program was also successful in attracting children' interest and enthusiasm, implying that it may be advantageous in other ways, too.

Due to paucity of relevant studies, our findings could only be partially compared with those of Arzoglou et al. (2013). In that study, a similar program (8-week long, delivered three times per week) was implemented to 15-19-year-old children with ASD, with the aim of examining its usefulness to contribute to the development of children' neuromuscular coordination. Its results manifested that the respective program had a positive influence in children' general coordination level by inducing significant improvements in all the skills that were measured through the following tasks: walking backwards, jumping on one foot, jumping sideway (left and right), sideways movement and repositioning. Even though the entire spectrum of fine and gross motor skills were not assessed by these tasks, it is obvious that due to their participation in the intervention program, children reinforced their ability to perform balance and other coordination skills. Therefore, both the findings of the above study and ours feature the importance of GTD to compromise potential delays in motor development of children with ASD.

In general terms, it seems that dance of various forms can be advantageous for children of this population. In particular, the positive impact of the so-called "therapeutic dance" on children's with ASD motor and psychosocial development has been pointed out by the findings of several case studies conducted during the past decades (KalishWeiss, 1982; Parteli, 1995). Although the programs that were implemented in these studies had various durations and the children that were examined belonged to different development stages (from 2.5 to 7 years), the value of these programs was indicative. More recent studies having investigated the influence of 15-24-session music/movement programs have similarly showed that children (from middle childhood to early 
adolescent) with ASD can be positively affected by the application of such programs, mainly in relation to the development of their balance and certain coordination skills (Imankhah et al., 2018; Sanglakh et al., 2017).

Interestingly, balance is referred as the main positive outcome in several other studies concerning children with ASD (Casey et al., 2015; Kim et al., 2016; Saracoglu \& Sirinkan, 2016; Shim et al., 2019). In these studies, different-type movement programs of 15-36 sessions, e.g., therapeutic ice-skating (Casey et al., 2015), Taekwondo (Kim et al., 2016), pilates (Saracoglu \& Sirinkan, 2016), cycling (Shim et al., 2019), were implemented in children 6-13 years old. In line with our findings, not only balance but also the general MC level of children of similar age measured by the BOT, was improved after the application of intervention programs informed by alternative PAs, such as horsing (Wuang et al., 2010) and table tennis (Pan et al., 2017). Important changes in children' motor skills and parameters of physical fitness were also observed in children with ASD that participated in a 14-week swimming program (Fragala-Pinkham et al., 2011). The large variety of programs utilized in the above studies proves that there are many alternatives in supporting these children' motor development; however, dance and specifically GTD programs seem to be a feasible solution, since no demanding or expensive equipment is needed for their delivery.

At this point, it should be noted that in some of the above studies longer intervention programs were applied compared to ours (Casey et al., 2015; FragalaPinkham et al., 2011; Pan et al., 2017; Sanglakh et al., 2017; Saracoglu \& Sirinkan, 2016; Wuang et al., 2010). Even though considerable adjustments were made by our children within the 8-week program adopted in the study, it cannot be ignored that the parameter of time is very important for children with ASD, so probably the adjustments made would have been even greater if a longer program had been applied.

Although this is the first study to offer some indication for the importance of Greek traditional dance in fostering the MC level of children with ASD, it has several limitations which should be considered when interpreting its results. First, only 14 children displaying heterogeneity participated in the study. However, this limitation is common for studies dealing with this population (Casey et al., 2015; Teixeira-Machado, 2015). In addition, this was a multiple single case study; therefore, causal inference cannot be suggested. Randomized control trials that will recruit larger sample sizes to examine even longer relative programs are needed if the effect of GTD on the MC of children's with ASD is to be fully realized. Furthermore, the examination of this effect in relation to the severity of ASD characteristics is of some value for designing advantageous personalized interventions.

Due to the distinctively low MC level of children with ASD, the "exposure" of these children to various programs and interventions targeting their motor development is imperative. In line with the results of this study, GTD is a suitable, pleasant, and quite effective activity to inform the content of such programs and interventions either as part of the curriculum of special education schools or as organized PA in after school settings. 
Nevertheless, despite its potential to improve all sort of motor skills to some extent, it seems that balance and body coordination skills are mostly affected by participating in it. Therefore, for challenging the development of all aspects of their $\mathrm{MC}$, children should be encouraged to take part in a variety of movement programs.

\section{Conclusion}

The present study examined whether a dance program, informed by GTD, could have a positive effect on the MC of children with ASD. Based on the results of the multiple single subject design adopted in this study, it was observed that the general MC level of all participants was considerably low; however, children who underwent the GTD program showed greater improvement in their MC compared to their peers that did not participate in it. Balance and body coordination skills were mostly affected by the program. Even though the results of this study stress the positive effect of GTD on the MC of children with ASD, future studies employing wider sample sizes and/or implementing longer programs are required to further confirm its merit.

\section{Conflict of Interest Statement}

The authors declare no conflicts of interests.

\section{About the Authors}

Evaggelia-Anna Marouli (MSc), teacher of Greek Traditional Dance, School of Physical Education \& Sports Science, Democritus University of Thrace, Greece.

Vasiliki Kaioglou (MSc, PhD candidate), School of Physical Education \& Sports Science, National and Kapodistrian University of Athens, Greece.

Vasilios Karfis (PhD), Specialized educational staff in Greek Traditional Dance, School of Physical Education \& Sports Science, National and Kapodistrian University of Athens, Greece.

Antonios Kambas (PhD), Professor, School of Physical Education \& Sports Science, Democritus University of Thrace, Greece.

Maria Koutsouba (PhD), Professor, School of Physical Education \& Sports Science, National and Kapodistrian University of Athens, Greece.

Fotini Venetsanou (PhD), Associate Professor, School of Physical Education \& Sports Science, National and Kapodistrian University of Athens, Greece.

\section{References}

Arzoglou D, Tsimaras V, Kotsikas G, Fotiadou E, Sidiropoulou M, Proios M, Bassa E, 2013. The effect of a traditional dance training program on neuromuscular 
coordination of individuals with autism. Journal of Physical Education and Sport, 13: 4, 563.

Bruininks RH, Bruininks BD, 2005. Bruininks-Oseretsky Test of Motor Proficiency. 2nd ed. Minneapolis, MN: NCS Pearson.

Casey AF, Quenneville-Himbeault G, Normore A, Davis H, Martell SG, 2015. A therapeutic skating intervention for children with autism spectrum disorder. Pediatric Physical Therapy, 27: 2, 170-177. doi: 10.1097/PEP.0000000000000139

Fragala-Pinkham MA, Haley SM, O'Neil ME, 2011. Group swimming and aquatic exercise programme for children with autism spectrum disorders: a pilot study. Developmental Neurorehabilitation, 14: 4, 230-241.doi: $\underline{10.3109 / 17518423.2011 .575438}$

Gandotra A, Kotyuk E, Szekely A, Kasos K, Csirmaz L, Cserjesi R, 2020. Fundamental movement skills in children with autism spectrum disorder: A systematic review. Research in Autism Spectrum Disorders, 78: 101632. doi: 10.1016/j.rasd.2020.101632

Gkotzia E, Venetsanou F, Kambas A, 2017. Motor proficiency of children with autism spectrum disorders and intellectual disabilities: A review. European Psychomotricity Journal, 9: 1, 46-69.

Green D, Charman T, Pickles A, Chandler S, Loucas T, Simonoff E, Baird G, 2009. Impairment in movement skills of children with autistic spectrum disorders. Developmental Medicine \& Child Neurology, 51: 4, 311-316. doi: 10.1111/j.14698749.2008.03242.x

Harris SR, 2017. Early motor delays as diagnostic clues in autism spectrum disorder. European Journal of Pediatrics, 176: 9, 1259-1262. doi: 10.1007/s00431-017-2951-7

Hildebrandt M, Koch S, Fuchs T, 2016. "We dance and find each other" 1: Effects of dance/movement therapy on negative symptoms in autism spectrum disorder. Behavioral Sciences, 6: 4, 24. doi: 10.3390/bs6040024

Imankhah F., Khanzadeh AAH, Hasirchaman A, 2018. The effectiveness of combined music therapy and physical activity on motor coordination in children with autism. Iranian Rehabilitation Journal, 16: 4, 405-412. doi: 10.32598/irj.16.4.405

Jaakkola T, Huhtiniemi M, Salin K, Seppälä S, Lahti J, Hakonen H, Stodden DF, 2019. Motor competence, perceived physical competence, physical fitness, and physical activity within Finnish children. Scandinavian journal of medicine \& science in sports, 29: 7, 1013-1021. doi: 10.1111/sms.13412

Kalish-Weiss B, 1982. Clinical and objective assessment of a multi-handicapped child. Unpublished manuscript.

Kim Y, Todd T, Fujii T, Lim JC, Vrongistinos K, Jung T, 2016. Effects of Taekwondo intervention on balance in children with autism spectrum disorder. Journal of Exercise Rehabilitation, 12: 4, 314. doi: 10.12965/jer.1632634.317 
Lai MC, Lombardo MV, Chakrabarti B, Baron-Cohen S, 2013. Subgrouping the autism "spectrum": reflections on DSM-5. PLoS Biology, 11: 4, e1001544. doi: 10.1371/journal.pbio.1001544

Lenroot RK, Yeung PK, 2013. Heterogeneity within autism spectrum disorders: what have we learned from neuroimaging studies?. Frontiers in Human Neuroscience, 7: 733. doi: $10.3389 /$ fnhum.2013.00733

Liu T, Hamilton M, Davis L, ElGarhy S, 2014. Gross motor performance by children with autism spectrum disorder and typically developing children on TGMD-2. Journal of Child and Adolescent Behaviour, 2: 1, 1000123. doi: 10.4172/2375-4494.1000123

Lucas BR, Latimer J, Doney R, Ferreira ML, Adams R, Hawkes G, et al. 2013. The Bruininks-Oseretsky test of motor proficiency-short form is reliable in children living in remote Australian aboriginal communities. BMC Pediatrics, 13: 1-12. doi: $\underline{10.1186 / 1471-2431-13-135}$

Lykesas G, Dania A, Koutsouba M, Nikolaki E, Tyrovola V, 2017. The effectiveness of a music and movement program for traditional dance teaching on primary school students' intrinsic motivation and self - reported patterns of lesson participation. Mediterranean Journal of Social Sciences, 8: 1, 227-236. doi: $\underline{10.5901 / \text { mjss.2017.v8n1p227 }}$

MacDonald M, Lord C, Ulrich DA, 2014. Motor skills and calibrated autism severity in young children with autism spectrum disorder. Adapted Physical Activity Quarterly, 31: 2, 95-105. doi:10.1123/apaq.2013-0068

Mathe D, Koutsouba M, Lykesas G, 2008. Critical overview of the hitherto suggested teaching methods of Greek traditional dance in Greece. Proceedings of the 22nd World Congress on Dance Research (pp. 1-17). Athens: International Dance Council.

Mottron L, Bzdok D, 2020. Autism spectrum heterogeneity: fact or artifact?. Molecular Psychiatry, 1-8. doi: 10.1038/s41380-020-0748-y

Najafabadi MG, Sheikh M, Hemayattalab R, Memari AH, Aderyani MR, Hafizi S, 2018. The effect of SPARK on social and motor skills of children with autism. Pediatrics \& Neonatology, 59: 5, 481-487. doi: 10.1016/j.pedneo.2017.12.005

Newschaffer CJ, Croen LA, Daniels J, Giarelli E, Grether JK, Levy SE, ... Reynolds AM, 2007. The epidemiology of autism spectrum disorders. Annual Revision of Public Health, 28: 235-258. doi: 10.1146/annurev.publhealth.28.021406.144007

Pan CY, 2008. Objectively measured physical activity between children with autism spectrum disorders and children without disabilities during inclusive recess settings in Taiwan. Journal of Autism and Developmental Disorders, 38: 7, $1292-$ 1301. doi: $10.1007 / \mathrm{s} 10803-007-0518-6$

Pan CY, 2014. Motor proficiency and physical fitness in adolescent males with and without autism spectrum disorders. Autism, 18: 2, 156-165. doi: $\underline{10.1177 / 1362361312458597}$ 
Pan CY, Chu CH, Tsai CL, Sung MC, Huang CY, Ma WY, 2017. The impacts of physical activity intervention on physical and cognitive outcomes in children with autism spectrum disorder. Autism, 21: 2, 190-202. doi: 10.1177/1362361316633562

Pan CY, Tsai CL, Chu CH, 2009. Fundamental movement skills in children diagnosed with autism spectrum disorders and attention deficit hyperactivity disorder. Journal of Autism and Developmental Disorders, 39: 12, 1694. doi: 10.1007/s10803$\underline{009-0813-5}$

Parteli L, 1995. Contribution of dance/movement therapy to the psychic understanding of motor stereotypes and distortions in autism and psychosis in childhood and adolescence. The Arts in Psychotherapy, 22: 241-247. doi: 10.1016/01974556(95)00033-2

Provost B, Lopez BR, Heimerl S, 2007. A comparison of motor delays in young children: autism spectrum disorder, developmental delay, and developmental concerns. Journal of Autism and Developmental Disorders, 37: 2, 321-328. doi: 10.1007/s10803-006-0170-6

Sanglakh Goochan Atigh A, Akbarfahimi M, Alizadeh Zarei M, 2017. The effect of movement activities in synchronization with music on motor proficiency of children with autism. Journal of Advanced Medical Sciences and Applied Technologies, 3: 2, 61-68. doi: 0.18869/nrip.jamsat.3.2.61

Saraçoğlu RN, Şirinkan A, 2016. The research of the effect of the Pilates special movement training program which is applied to autism spectrum students on students balance and flexibility properties. European Journal of Physical Education and Sport Science, 2: 2, 90- 99.

Shim A, Newman D, Haegele J, Varnado K, 2019. The effects of a pedal-less bicycle intervention on stability scores among children with autism spectrum disorder. Advances in Neurodevelopmental Disorders, 1-7. doi: 10.1007/s41252-019-00131-z

Teixeira-Machado L, 2015. Dance therapy in autism: a case report. Fisioterapia e Pesquisa 22: 2, 205-211. https://doi.org/10.590/1809-2950/11137322022015

Tyrovola V, 2001. O ellinikos choros: mia diaforetiki prosegisi [Greek dance: a different approach.] Athens, Greece: Gutenberg.

Venetsanou F, Donti O, Koutsouba M, 2014. The effect of music/movement program on preschooler's motor rhythmic ability. European Psychomotricity Journal, 6: 1, 6073.

Venetsanou F, Kambas A, 2004. How can a traditional Greek dances programme affect the motor proficiency of pre-school children? Research in Dance Education, 5: 2, 127-138. doi: 10.1080/14617890500064019

Venetsanou F, Voukias K, Zavolas G, Mitsios O, Kambas A, 2016. Aspects of validity and reliability of the Bruininks-Oseretsky Test of Motor Proficiency in Greek children. 21th Annual Congress of the ECSS, 6-9 July Vienna.

Volkmar F, Chawarska K, Klin A, 2005. Autism in infancy and early childhood. Annual Review of Psychology, 56: 315-336. doi: 10.1146/annurev.psych.56.091103.070159 
Wengrower H, 2010. I am here to move and dance with you. Arts therapies in schools. Research and practice, 179-196.

Wuang YP, Wang CC, Huang MH, Su CY, 2010. The effectiveness of simulated developmental horse-riding program in children with autism. Adapted Physical Activity Quarterly, 27: 2, 113-126. doi: 10.1123/apaq.27.2.113 be applied to their work. Under the terms of this license, no permission is required from the author(s) or publisher for members of the community to copy, distribute, transmit or adapt the article content, providing a proper, prominent and unambiguous attribution to the authors in a manner that makes clear that the materials are being reused under permission of a Creative Commons License. Views, opinions and conclusions expressed in this research article are views, opinions and conclusions of the author(s). Open Access Publishing Group and European Journal of Physical Education and Sport Science shall not be responsible or answerable for any loss, damage or liability caused in relation to/arising out of conflict of interests, copyright violations and inappropriate or inaccurate use of any kind content related or integrated on the research work. All the published works are meeting the Open Access Publishing requirements and can be freely accessed, shared, modified, distributed and used in educational, commercial and non-commercial purposes under a Creative Commons attribution 4.0 International License (CC BY 4.0). 